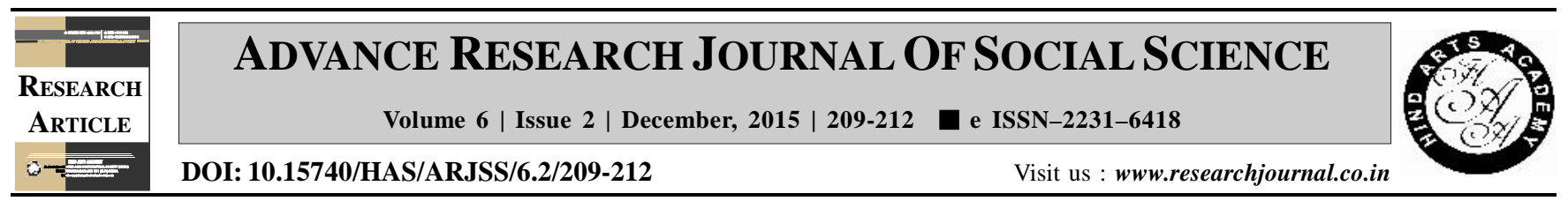

\title{
A comparative study on life satisfaction among male and female employees
}

Nidhi Singh* and G. Tiwari

Department of Human Development and Family Studies, Maharana Pratap University of Agriculture and Technology, UDAIPUR (RAJASTHAN) INDIA

\section{ARTICLE INFO :}

Received

Revised

: 26.09 .2015

Accepted

: 03.11 .2015

: 12.11 .2015

KEY WORDS :

Life satisfaction, Banking sectors, Male employees; Female employees

\section{HOW TO CITE THIS ARTICLE :}

Singh, Nidhi and Tiwari, G. (2015). A comparative study on life satisfaction among male and female employees. $A d v$. Res. J. Soc. Sci., 6 (2) : 209-212.

*Author for correspondence

\begin{abstract}
Present study compared life satisfaction among male and female employees working in banking sector. Udaipur City (Rajasthan) was the locale of study. The sample for the study comprised 60 male and 60 female employees ( 30 from Public and 30 from Private Banks, respectively). Age group of the samples was 20-60 years. Life satisfaction was assessed by LS-Scale developed by Dr. Q.G. Alam and Dr. Ramji Srivastava. Results find that there is no significance difference found in life satisfaction among male and female employees.
\end{abstract}

